\title{
A teacher's engagement with learner errors in her Grade 9 mathematics classroom
}

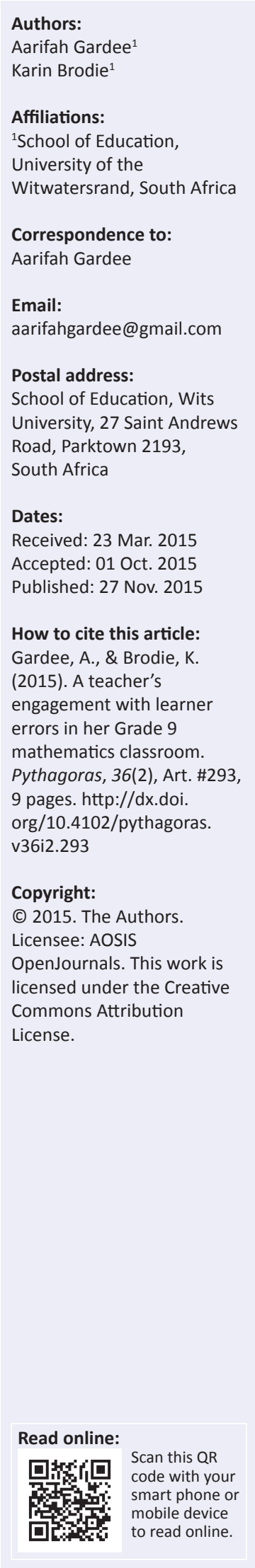

How errors are dealt with in a mathematics classroom is important as it can either support or deny learner access to mathematical knowledge. This study examines how a teacher, who participated in a professional development programme that focused on learner errors, engaged with mathematical errors in her Grade 9 classroom. Data were collected over a twoyear period in the form of videotapes and were analysed qualitatively. Our findings illustrate that this teacher dealt with four types of mistakes: slips, errors derived from misconceptions, language-related errors and errors that occurred from the incorrect usage of the calculator. She dealt with these by correcting, probing or embracing them. We found that, over time, this teacher dealt with more errors and corrected and embraced errors in different ways. We recommend that teachers use their professional knowledge to decide when, why and how it is appropriate to correct, probe or embrace errors in light of their knowledge of the content and their learners.

\section{Introduction}

Errors play a central role in the mathematics classroom as they are a reflection of the manner in which learners reason and they illuminate the processes through which learners attempt to construct their own knowledge (Olivier, 1989). Errors can be used by teachers to provide learners with epistemological access to mathematics and contribute to developing learners' conceptual understanding (Brodie, 2013). Therefore, the manner in which a teacher deals with learner errors is crucial, as it can either enhance or limit learners' understanding of mathematics. Methodologies for remediating errors are not always satisfactory, especially when additional work or reexplaining of ideas are used as remedies (Borasi, 1987). While much research has been done on the nature of learners' errors and their underlying misconceptions (Hansen, 2011; Nesher, 1987; Olivier, 1989) and how teachers might deal with errors (Borasi, 1994; Swan, 2001), very little work has illustrated how teachers actually deal with errors in their mathematics classrooms (Heinze \& Reiss, 2007).

The purpose of this study is to investigate the type of errors a teacher chooses to deal with in her mathematics classroom and the manner in which she deals with the errors. Since the data from this study were obtained over a two-year period, we also decided to investigate if there were any shifts in the teacher's practice in dealing with errors over time. This research is part of a larger project called the Data-Informed Practice Improvement Project (DIPIP). DIPIP works with mathematics teachers in professional learning communities so that they may develop their understanding of the importance of mathematical errors in the classroom and the learners' reasoning behind their errors and collectively strategise how to deal with them (Brodie, 2013).

The first and second sections of this article draw on the literature to illuminate the kinds of errors that might occur in the classroom and the ways in which teachers might deal with errors. In the third section, we explain the research design and methodology used to analyse our data, which is then followed by an analysis and discussion of our results in the fourth section. Finally, we suggest recommendations based on our findings.

\section{Slips, errors and misconceptions}

There are many reasons why learners may not obtain the correct solution to a mathematical problem. These reasons may include, but are not limited to, carelessness, a lack of knowledge of the mathematical concepts or the learners not understanding what is required of them in a mathematical task (Swan, 2001). Terms like 'misconceptions', 'errors' and 'mistakes' are often used interchangeably to describe any solution that is a deviation from the expected result. However, these three terms are not synonymous and refer to different kinds of mistakes. The first is what Olivier (1989, p. 12) calls 'slips', which are mistakes made as a result of carelessness and which are easily rectified when pointed out. Slips are not symptoms of conceptual misunderstandings. 
Slips are common; we all make them as learners and doers of mathematics.

Slips are sporadic. Errors, however, are systematic. They occur on a regular basis and are pervasive and persistent, often across contexts. Errors occur at a deeper conceptual level than slips, so correcting errors is usually not enough to address these conceptual misunderstandings. The underlying conceptual framework that causes the errors is called a misconception (Nesher, 1987). Nesher argues that misconceptions lead to a cluster of errors, which are not sporadic.

Misconceptions generate errors. But how are misconceptions generated? The theory of constructivism proposes that we actively construct knowledge by using our prior knowledge as a foundation to build new knowledge. The processes of assimilation and accommodation enable us to restructure our existing schemas to develop our conceptual knowledge (Hatano, 1996). Assimilation occurs when new knowledge is 'amalgamated' into existing schema (Hatano, 1996, p. 202). Accommodation occurs when new knowledge is in conflict with existing schema and reorganisation of the schema needs to occur to incorporate the new knowledge. Assimilation and accommodation working together lead to the reconstruction of knowledge (Hatano, 1996), which means that learners are not only actively engaging in constructing knowledge, but they are also reorganising their knowledge into more powerful schema. The process of accommodating new knowledge is more challenging than assimilating knowledge into existing schema. By attempting to assimilate knowledge that we should accommodate, we tend to 'overgeneralise' new knowledge based on prior correct knowledge (Olivier, 1989). We apply knowledge that is correct in one domain to another in which it no longer works (Smith, DiSessa \& Roschelle, 1993). This is why errors are not random; they have some grounding in learners' correct prior knowledge. A constructivist framework suggests that errors are sensible and reasonable to learners and that they illuminate important aspects of learners' reasoning, both valid and not valid. DIPIP focuses on working with teachers to understand the reasoning behind learner errors and to build on this reasoning to develop new mathematical concepts (Brodie, 2013, 2014).

\section{How teachers deal with misconceptions}

The word 'error' in the education system tends to have negative connotations. Summative assessments used widely in schools perpetuate the misconception that making errors is punishable through the system of deducting marks for wrong performances (Nesher, 1987). Treating errors as problems may disrupt learners' confidence in their previously learned correct knowledge (Nesher, 1987). Ingram, Baldry and Pitt (2013) argue that although teachers may not explicitly tell the learners that making errors is problematic, the manner in which teachers deal with errors, by avoiding opportunities for learners to make and discuss mistakes in the classroom, implicitly suggests that errors are problematic (Heinze \&
Reiss, 2007). Hansen (2011) argues that teachers need to treat errors sensitively and productively, as errors can be used as tools, not only to motivate learners but also to assist them in developing their conceptual knowledge by learning from their errors. Teachers may also regard errors as a failure on their part. This is reflected in Brodie's (2014) research, wherein teachers blamed the learners or themselves for the errors made in class.

Much of the research on errors and misconceptions argues that errors are a normal part of the learning process (Borasi, 1987; Brodie, 2013, 2014; Heinze \& Reiss, 2007; Ingram et al., 2013; Nesher, 1987; Smith et al., 1993). Even experienced mathematicians make errors and in so doing create new knowledge (Borasi, 1994). In classrooms, errors make for points of engagement with learners' current knowledge (Brodie, 2014). This notion of errors gives us a way to help teachers see learners as reasoning and reasonable thinkers and the practice of mathematics as reasoned and reasonable (Ball \& Bass, 2003). If teachers search for ways to understand why learners may have made errors, they may come to value learners' thinking and find ways to engage their current knowledge in order to create new knowledge. An important issue for teachers' thinking about errors relates to the role and responsibility of teachers in producing errors. Errors are seldom taught directly by teachers and yet all learners, even 'strong' learners, develop them at some point (Brodie, 2014). However, teachers sometimes exacerbate errors through taken-for-granted use of language and concepts (Brodie, 2014) and, at another level, through not making errors public and dealing with them (Brodie, 2014; Ingram et al., 2013).

Research on teachers' dealing with learner errors in mathematics is limited, but two authors have developed frameworks for this purpose. Peng and Luo (2009) identify four kinds of error analysis that teachers can use to engage with learners' written texts: identify, interpret, evaluate and remediate. In two case studies they report on, the teachers were able to identify the learners' errors but struggled to interpret them appropriately. They were therefore not able to appropriately evaluate or remediate the errors. In a study with 45 pre-service teachers, Prediger (2010) asked them to analyse a learner's error and their analyses suggests four characteristics necessary for diagnostic competence of learner errors: interest in learner thinking, interpretive attitude of understanding the learner's thinking from their perspective, general knowledge of learning processes and domain-specific mathematical knowledge. Most of the preservice teachers in Prediger's study showed an interest in understanding the learners' errors but those who did not have an interpretive attitude were likely to make suggestions for remediation that were confusing or that re-taught what the learner already knew, rather than pinpointed the source of the error. Pre-service teachers who showed an interpretive attitude with some general knowledge of learning were able to partially understand how the learners might be thinking but were not able to activate the mathematical knowledge that they needed to fully understand and work with the error. Only pre-service teachers who activated all four levels of competence were able to make appropriate interventions. 
While Peng and Luo (2009) and Prediger (2010) use the notion of remediation of learner errors, Borasi (1994) argues that there is a difference between diagnosing and remediating errors, with the aim of eliminating them, and using them as 'springboards for inquiry' where errors become part and parcel of mathematical development and knowledge creation (see also Lakatos, 1976).

Based on the above, Brodie (2013) suggests a framework for analysing how teachers interact with learner errors. Teachers can avoid, correct, probe or embrace errors. Teachers may avoid or ignore errors because they are insecure about their content knowledge, they may not regard errors as important tools for learning, they may not want to shame learners or they fear that errors may be 'contagious' (Swan, 2001, p. 151). Teachers often correct errors, thereby making the correct knowledge accessible to the learners. Correcting errors suggests that teachers have identified and evaluated the errors rather than interpreted the errors from the learners' perspectives. Probing errors involves teachers attempting to understand how errors make sense to learners, usually by asking learners 'probing questions or pressing questions' to gain access to learner thinking (Brodie \& Shalem, 2011, p. 431). By asking such questions, teachers support learners to develop reasoning and learners learn to explain their thinking and justify their ideas. Embracing errors is where teachers use errors constructively to generate new knowledge for the learner who has made the error and for other learners (Brodie, 2013); that is, they use errors as tools to enhance epistemological access. We use this framework to analyse how the teacher in this study dealt with the errors her learners produced.

\section{Research design and methodology}

The teacher whose lessons we analysed participates in a professional learning community organised by DIPIP on an ongoing basis. This teacher is one of about 40 teachers who are part of this project and was selected for this study because she seemed to have a range of strategies in working with learner errors. The data are in the form of videotapes, which were taken before the project started as a baseline and have been collected at various points during the project over two years (2012-2013). For the purpose of this study, we analysed nine videotaped lessons in a Grade 9 class. Each of the nine lessons was categorised by the DIPIP project as either individually planned or jointly planned lessons. Individually planned lessons involved the teacher teaching a lesson planned by herself as part of her daily routine. The jointly planned lessons were planned in collaboration with other teachers in the professional learning community and aimed to deal with the possible learner errors that might emerge during the lessons ${ }^{1}$. In each year (year 1 and year 2) there was a set of individually planned and jointly planned lessons. Table 1 provides an overview of the types of lessons.

1. See Brodie and Shalem (2011) for a description of the DIPIP activities and how the jointly planned lessons arose out of previous error analysis.
TABLE 1: Overview of the types of lessons.

\begin{tabular}{|c|c|c|c|c|}
\hline $\begin{array}{l}\text { Lesson } \\
\text { category }\end{array}$ & $\begin{array}{l}\text { Number } \\
\text { of lessons }\end{array}$ & Date & $\begin{array}{c}\text { Duration } \\
\text { (minutes) }\end{array}$ & Topic \\
\hline \multirow[t]{3}{*}{$\begin{array}{l}\text { Individually } \\
\text { planned } 1\end{array}$} & 3 & 20 April 2012 & 30 & $\begin{array}{l}\text { Algebra: dealing } \\
\text { with three revision } \\
\text { questions }\end{array}$ \\
\hline & & 25 April 2012 & 30 & Polygons \\
\hline & & 4 May 2012 & 30 & $\begin{array}{l}\text { Revision of algebra and } \\
\text { properties of triangles }\end{array}$ \\
\hline \multirow[t]{2}{*}{$\begin{array}{l}\text { Jointly } \\
\text { planned } 1\end{array}$} & 2 & 17 August 2012 & 25 & $\begin{array}{l}\text { Algebra: equations and } \\
\text { expressions }\end{array}$ \\
\hline & & 20 August 2012 & 35 & $\begin{array}{l}\text { Algebra: equations and } \\
\text { expressions }\end{array}$ \\
\hline \multirow[t]{3}{*}{$\begin{array}{l}\text { Individually } \\
\text { planned } 2\end{array}$} & 3 & 19 April 2013 & 35 & $\begin{array}{l}\text { Algebra: laws of } \\
\text { exponents }\end{array}$ \\
\hline & & 22 April 2013 & 35 & $\begin{array}{l}\text { Algebra: simplification } \\
\text { of expressions }\end{array}$ \\
\hline & & 23 April 2013 & 35 & Ratios \\
\hline $\begin{array}{l}\text { Jointly } \\
\text { planned } 2\end{array}$ & 1 & $\begin{array}{l}17 \text { September } \\
2013\end{array}$ & 35 & Revision of ratios \\
\hline
\end{tabular}

The first step in data analysis was to watch each of the videos. The first author made notes on the time that an error was seen in the video, the nature of the error and the manner in which the teacher dealt with the error. To further ensure the validity of our results, she re-watched the video and documented excerpts illustrating how the teacher dealt with the error and the possible reasons that the learners provided for making such errors, if they were expressed. The first author then discussed her coding system and checked her interpretations with the second author and all disputes were resolved by discussion. Thereafter, we arranged the data into a table. We documented the error, our thoughts on the error, the manner in which the teacher dealt with the error and our thoughts on the teacher's approach to dealing with the error in light of the literature.

Initially, we intended to classify errors using the two categories, slips and errors stemming from misconceptions, extracted from our literature review. However, when watching the lessons, we realised that there were two additional types of errors which are conceptual in nature; that is, they are not slips, but are not derived from misconceptions. These conceptual errors were languagerelated errors and errors derived from the incorrect usage of the calculator, which we included in our framework. We then classified each of the errors in our table of results as either being a slip, an error derived from a misconception, a language-related error or an error derived from incorrect usage of the calculator. The manner in which the teacher dealt with the error was classified as correcting the error, probing into the error or embracing the error, as discussed above.

We acknowledge that the practices of one teacher cannot be generalised to other teachers in the project, or to other teachers more generally. However, this analysis has enabled us to test and refine our categories for analysis and we intend to analyse the shifts among other teachers in the future. The analysis of one teacher is useful in that it enables us to discuss in detail the different categories and how she developed her practices over time. 


\section{Analysis and discussion of results}

\section{Mistakes that occurred in the classroom}

There were four categories of mistakes that occurred in in the classroom: slips, errors derived from misconceptions, language-related errors and errors derived from incorrect usage of the calculator. To illustrate the nature of each category of mistakes we provide an example of each category below.

An example of a slip occurred when the teacher asked learners how many times 2 goes into 36. A learner responded by saying 13 . This learner could have treated 36 as 26 . At a Grade 9 level, this error can be attributed to carelessness and can be easily corrected by checking the calculation. At this level, it is unlikely that the mistake indicates a conceptual misunderstanding; hence, it can be classified as a slip.

An example of an error derived from a misconception occurred when the teacher asked the learners to add $\frac{5}{10}$ to $\frac{7}{8}$. A learner gave an incorrect answer of one and a half. Since the teacher did not probe the error, we thought of possible methods to get the answer. The first possible error is that the learner may have added the numerator and the denominator separately:

$$
\frac{5}{10}+\frac{7}{8}=\frac{12}{18}
$$

This error is evidence of a misconception because the learner overgeneralised the addition of whole numbers to the addition of fractions. The learner could have also added the numerator and denominator based on an overgeneralisation of multiplication and division of fractions. Much research suggests that misconceptions are a result of prior correct knowledge interfering with new knowledge. However, new learning, such as the multiplication and division of fractions can also interfere with prior correct learning (Olivier, 1989). The second error in this answer is that the learner divided 18 by 12 instead of 12 by 18 to simplify the fraction. This learner probably assumed that 12 divided by 18 is equivalent to 18 divided by 12 , a misconception that can maybe be attributed to the overgeneralisation of the commutative properties of addition and multiplication of numbers to division.

An example of a language-related error occurred when the teacher asked the learners for a definition of the word 'expression'. A learner stated that an expression refers to 'making a number bigger', which suggests that this learner confused the word 'expression' with 'expansion'. Despite their similar pronunciations, these concepts refer to different mathematical objects or processes and have different spellings (Adams, 2003). We classified this as a language-related error and not a slip because such errors are reasonable and sensible and usually occur where learners do not fully grasp the concepts. This learner did not fully grasp the concept of an expression in mathematics and used it interchangeably with the word expansion. Language-related errors are likely to occur across learners, rather than be idiosyncratic, once again highlighting the reasonableness of such errors.

An example of an error due to the incorrect usage of the calculator occurred when the teacher asked the learners how to represent $-1 x$ in the expression $-3 x^{2}-1 x$. A learner stated that negative one is like zero. When probed by the teacher, the learner said that she used a calculator to obtain the answer of zero. There is a tendency for variables in a scientific calculator on computer mode to represent numbers saved in its memory. If there is no number saved within the memory, variables are equated with zero. Hence, by typing an expression into a scientific calculator, learners may get incorrect answers. In classifying errors linked to the incorrect usage of the calculator, it was established in the classroom by both the teacher and the learners that a calculator was used to get the incorrect answers. These errors are conceptual because they relate to not understanding how the calculator works and are likely to be repeated and systematic in nature.

Table 2 illustrates the frequency of each of the four kinds of mistakes across the lessons that were analysed. There were a total of 69 mistakes made across the four lesson categories.

Most of the errors that were made across these four lesson categories arose from misconceptions. This indicates that the majority of the incorrect answers made across the analysed lessons were derived from an overgeneralisation of correct prior knowledge. Nesher (1987) argues that misconceptions give rise to a cluster of errors. This means that from one misconception, there can be many errors of a similar nature in each lesson category. This could possibly be the reason why the frequency of errors due to misconceptions is significantly higher than the other conceptual errors and slips.

\section{Errors dealt with by the teacher}

Of the 69 mistakes that were made across the four categories of lessons, 45 were dealt with by the teacher, while 24 were not. Some of these 24 mistakes were ignored by the teacher: she did not acknowledge or engage with the learners' responses and, in some cases, she may not have heard them. Others were ignored because they were shouted out, a deliberate strategy of this teacher.

Table 3 illustrates the number and the nature of the mistakes that were dealt with by the teacher and should be read in conjunction with Table 2.

TABLE 2: Types of errors that occurred per lesson category.

\begin{tabular}{llccccc}
\hline $\begin{array}{l}\text { Number } \\
\text { of } \\
\text { lessons }\end{array}$ & $\begin{array}{c}\text { Lesson } \\
\text { category }\end{array}$ & Slips & $\begin{array}{c}\text { Errors } \\
\text { derived from } \\
\text { misconceptions }\end{array}$ & $\begin{array}{c}\text { Language- } \\
\text { related } \\
\text { errors }\end{array}$ & $\begin{array}{c}\text { Incorrect } \\
\text { usage of the } \\
\text { calculator }\end{array}$ & Total \\
\hline 3 & $\begin{array}{l}\text { Individually } \\
\text { planned 1 }\end{array}$ & 6 & 16 & 0 & 0 & 22 \\
\hline 2 & $\begin{array}{l}\text { Jointly } \\
\text { planned 1 }\end{array}$ & 0 & 15 & 1 & 1 & 17 \\
\hline 3 & $\begin{array}{l}\text { Individually } \\
\text { planned 2 }\end{array}$ & 1 & 20 & 0 & 1 & 22 \\
\hline 1 & $\begin{array}{l}\text { Jointly } \\
\text { planned 2 } \\
\text { Total }\end{array}$ & 0 & 4 & 4 & 0 & 8 \\
\hline & $\mathbf{7}$ & $\mathbf{5 5}$ & $\mathbf{5}$ & $\mathbf{2}$ & $\mathbf{6 9}$ \\
\hline
\end{tabular}


TABLE 3: Number of different kinds of mistakes dealt with by the teacher.

\begin{tabular}{lccccc}
\hline $\begin{array}{l}\text { Lesson } \\
\text { category }\end{array}$ & Slips & $\begin{array}{c}\text { Errors } \\
\text { derived from } \\
\text { misconceptions }\end{array}$ & $\begin{array}{c}\text { Language- } \\
\text { related } \\
\text { errors }\end{array}$ & $\begin{array}{c}\text { Incorrect } \\
\text { usage of the } \\
\text { calculator }\end{array}$ & Total \\
\hline $\begin{array}{l}\text { Individually } \\
\text { planned 1 }\end{array}$ & 0 & 7 & 0 & 0 & 7 \\
$\begin{array}{l}\text { Jointly } \\
\text { planned 1 }\end{array}$ & 0 & 9 & 1 & 1 & 11 \\
$\begin{array}{l}\text { Individually } \\
\text { planned 2 }\end{array}$ & 1 & 17 & 0 & 1 & 19 \\
$\begin{array}{l}\text { Jointly } \\
\text { planned 2 }\end{array}$ & 0 & 4 & 4 & 0 & 8 \\
Total & 1 & 36 & 5 & 2 & 45 \\
\hline
\end{tabular}

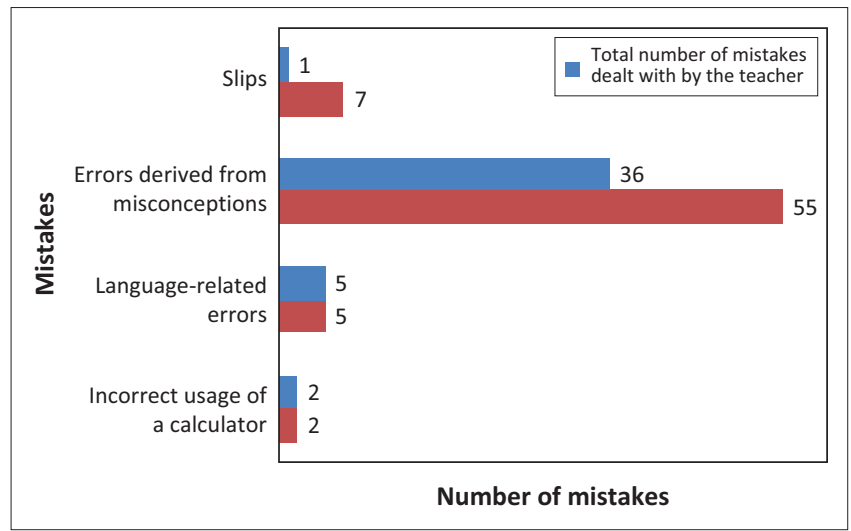

FIGURE 1: Number of mistakes dealt with by the teacher.

While Table 2 shows that there were a total of seven slips that occurred during the lessons, Table 3 shows that one slip was dealt with by the teacher. Similarly, of the 55 errors derived from misconceptions (Table 2), 36 were dealt with by the teacher (Table 3) and all of the five language-related errors and two incorrect usage of the calculator were dealt with (Table 2 and Table 3).

Figure 1 illustrates the number of mistakes in each category dealt with by the teacher (Table 3 ) in relation to the number of mistakes made in each category (Table 2).

Figure 1 illustrates that the teacher dealt with all the language-related errors as well as all the errors derived from the incorrect usage of the calculator. She further dealt with $65 \%$ of errors that were derived from misconceptions. Table 2 and Table 3 illustrate that most of the misconceptions that were not dealt with occurred during the first individually planned and jointly planned lessons. It is possible that the teacher may have benefited from her participation in her professional learning community as she dealt with more errors during the last two individually planned and jointly planned lessons. One of the seven slips that occurred during the lessons was dealt with by the teacher, which could be due to the fact that slips are not as serious as errors because they are sporadic and due to carelessness.

\section{How the teacher dealt with the errors}

We categorised the manner in which the teacher dealt with errors using Brodie's (2013) three categories: correcting errors, probing errors and embracing errors. There was one slip that was probed by the teacher. We have included it in the category of probing errors despite slips not being classed as errors. Examples of correcting, probing and embracing errors from the lessons are provided to show the reader how we coded our data.

The first example is an excerpt where the teacher corrected an error. In this excerpt, the teacher asked the learners to share 12 sweets according to the ratio 1:2:3. She asked different learners to answer how many sweets will be represented by 1,2 and 3 in the ratio:

Teacher: What is two parts of the twelve sweets?

Learner A: Four.

Teacher: That is four sweets. And now, I'm coming to this side, Learner B? What is three parts of twelve sweets?

Learner B: Three.

Teacher: Is three. Alright, I want people on this side to help Learner B. Because Learner B is sitting on this side. So what is three parts of twelve sweets, Learner C?

Learner C: Six.

Teacher: Six.

Learner B's response to how many sweets are represented by 3 in the ratio was incorrect. The teacher then asked another learner what the correct answer was and it was established to be 6 . Despite addressing the error, the teacher did not get to the bottom of why this error was made as she had another learner correct Learner B. We note here that even if the teacher gets another learner to correct the error, it still counts as correcting the error because the underlying conceptual issues are not dealt with. Borasi (1987) argues that this manner of correcting errors is ineffective as any learning that occurs may be temporary. This is because errors are evidence of conceptual misunderstanding and simply correcting them does not mean that the conceptual basis of this error is corrected. This is emphasised by Brodie (2013) who argues that the manner of correcting errors may not contribute to supporting learners' access to mathematical knowledge.

The second example is an excerpt of the teacher first probing an error and then embracing the error. In this excerpt, the teacher asked the learners to find $n+m+p$ if $n+m=11$. This is a very long excerpt. We have divided it into three smaller parts to make the discussion that follows easier to understand.

\section{Part A:}

Teacher: If $n$ plus $m$ is equal to eleven. Then what is $n$ plus $m$ plus $p$ ? Lift up your hand. If $n$ plus $m$ is equal to eleven. Then what is $n$ plus $m$ plus p? Learner $\mathrm{H}$ ?

Learner H: It might be fifteen and a half.

Teacher: It is fifteen and a half. And how did you get fifteen and a half? 
Learner H: Because $n$ is equal to five and a half and $m$ is equal to five and a half. So $p$ is five and a half again.

Teacher: Right. How do you ... Why do you get five and a half?

Learners: Sixteen and a half.

Teacher: Where do you get five and a half?

Learner $\mathrm{H}$ : Because five and a half plus five and a half is equal to eleven.

Teacher: Is there anything that tells us that should be solved like that?

Learners: [Inaudible]

Teacher: It's your mind set. Who else has got another answer for that sum? Because he, Learner $\mathrm{H}$, what did he ... did he divide that eleven by two. And why did he divide by two?

Learner H: Because half of eleven is five and a half.

Teacher: Because half of eleven is five and a half. So in other words, when you look at $n$ and you look at $m$, what do you see there? Look at $n$ and look at $m$. Because we are trying to find out why did you think of dividing that eleven by two? Where did you get that from?

Learner H: Because Mam, half of eleven is five and a half. And if you equal five and a half and five and a half, it gives you eleven.

\section{Part B:}

Teacher: Right. Learner I, do you want to say something?

Learner I: Mam, I think its eighteen Mam, because $m$ plus $n$ is equal to eleven. So $m$ can be five, $n$ can be six. So if it's $n$ plus $m$ plus $p$, then $m$ can be five, $n$ can be six and $p$ can be seven.

Teacher: Why did you say $m$ can be five, $n$ can be six. What informs you of that? What in that sum? What is $m$ and $n$ ? How do we call $m$ and $n$ in that sum?

Learners: Variables.

Teacher: They are?

Learners: [Shout out] Variables, unknown numbers.

Teacher: They are variables. What is a variable?

Learners: [Inaudible]

Teacher: Sssshhhh ... Learner J?

Learner J: That is a letter from the alphabet that represents a number.

\section{Part C:}

Teacher: That is a letter from the alphabet that represents a number. Right, so when Learner I said that $m$ can be represented by five, $n$ can be represented by six. So when we add both of those, it could be that $m$ is two and $n$ is nine. Or $m$ is seven and $n$ is ... What would $n$ be, if $m$ is seven? What would $n$ be?

Learner K: Four.
Teacher: It would be ... four. Alright. So we agree that $m$ and $n$ are variables there and they are representing numbers. So, they can be any number. Now why do you say $p$ is seven? Where do you get that from? Where do you get that from because we have just said that $m$ and $n$ are letters of the alphabet which are representing a number.

Learner: [Inaudible]

Teacher: $\quad$ OK, he says that because we say $m$ is five and $n$ is six, so automatically $p$ will be seven. But if I say to you $m$ is two and $n$ is nine. What would $p$ be?

Learner L: [Shout out] Ten.

Learner M: [Put up his hand] Mam, the answer is eleven plus $p$.

Teacher: The answer is eleven plus $p$.

In Part A of the excerpt, the teacher constantly probed Learner H's error. She asked him how he got the answer of $15 \frac{1}{2}$, why he got $5 \frac{1}{2}$ for $n$, whether there was any information in the problem that made him think that problem could be solved this way and continued to probe his error. The teacher responded to this error by interacting and engaging with the error to access the learner's reasoning and to support him in reflecting on his solution process. In Part B, the teacher used the same approach when dealing with Learner I's error. In both cases, the learners' reasoning clearly made sense to them, but would not make sense to a mathematician and did not make sense to the teacher. This is because the learners were assigning values to the variables which were not necessary according to the question.

By examining Part A and Part B, it is evident that the teacher uses the teaching strategy of questioning to probe the errors, for example by asking learners to justify their answers in a discussion as to why they thought the question should be solved in the manner they suggested. What makes this category of dealing with errors different from embracing errors is that she did not use these learner justifications to promote epistemological access.

In Part $C$, after obtaining a definition of variables from the learners, the teacher began to problematise the question. Using the definition that variables represent numbers, the teacher substituted different values that add up to 11 in place of $m$ and $n$ to show that these variables do not represent unique numbers. Finally, one of the learners gave the correct answer, which was explained later in the lesson. Throughout this excerpt, the teacher did not tell the learners at any point that they were wrong; instead she used questions to support the learners' understanding that the variables $m$ and $n$ can represent any two numbers whose sum is 11 .

The above excerpt illustrates that this teacher did not only tolerate errors, but used them for epistemological purposes. The learners had learned previously that there can be a finite set of values for variables in an equation and an infinite 
number in an expression. Here, the teacher further supported learners in developing a conceptual understanding of variables in equations and expressions through conversation. The manner in which the teacher dealt with the error enabled learners to perceive that their errors are reasonable and are an integral part of learning mathematics (Brodie, 2013). This excerpt indicates how errors can be embraced 'as a point of contact with learners' thinking and as points of conversation, which can generate discussions about mathematical ideas' (Brodie, 2013, p. 8) and contribute to the enrichment and development of mathematical knowledge.

What is interesting about all the errors that were embraced across the lessons is that the conversations were all lengthy and required a large amount of time. Hansen (2011) argues that dealing with misconceptions to enable learning is very time consuming. The exploration of mathematical ideas is encouraged by Brodie (2007), who argues that these conversations are important as they can foster an increase in genuine learner thinking.

Table 4 illustrates the number of errors that were corrected, probed or embraced by the teacher across the four categories of lessons.

Table 4 shows that the teacher corrected more errors in comparison to the number of errors she probed or embraced, which is a finding that might be expected of most teachers (Brodie, 2013). However, in the case of this teacher, 21 errors were either probed or embraced, which is similar to the number corrected, suggesting that this teacher was engaging errors in a way that is different from many teachers. This is unexpected and may be attributable to the work that the teacher did with her professional learning community in DIPIP. In order to investigate this suggestion further, we looked at shifts in how the teacher dealt with errors over time.

\section{Changes over time in dealing with errors}

There was a change in the manner in which the teacher dealt with errors across the four categories of lessons which took place over a two-year period. Table 4 shows that the teacher corrected and probed more errors over time but the number of errors embraced remained relatively constant. Table 5 shows the number and percentage of errors dealt with by the teacher per lesson category.

Table 5 illustrates that there was an increase in the percentage of errors dealt with by the teacher across the lessons: from

TABLE 4: The manner in which the teacher dealt with the errors.

\begin{tabular}{lcccc}
\hline Lesson category & Correcting errors & Probing errors & Embracing errors & Total \\
\hline $\begin{array}{l}\text { Individually } \\
\text { planned 1 }\end{array}$ & 3 & 1 & 3 & 7 \\
$\begin{array}{l}\text { Jointly planned 1 } \\
\begin{array}{l}\text { Individually } \\
\text { planned 2 }\end{array}\end{array}$ & 5 & 3 & 3 & 11 \\
Jointly planned 2 & 10 & 6 & 3 & 19 \\
Total number & 24 & 0 & 2 & 8 \\
\hline
\end{tabular}

TABLE 5: Number and percentage of errors dealt with by the teacher per lesson category.

\begin{tabular}{lccc}
\hline Lesson category & $\begin{array}{c}\text { Total number } \\
\text { of errors }\end{array}$ & $\begin{array}{c}\text { Total number of } \\
\text { errors dealt with by } \\
\text { the teacher }\end{array}$ & $\begin{array}{c}\text { Percentage of errors } \\
\text { dealt with by the } \\
\text { teacher }\end{array}$ \\
\hline $\begin{array}{l}\text { Individually } \\
\text { planned 1 }\end{array}$ & 22 & 7 & 31.8 \\
Jointly planned 1 & 17 & 11 & 64.7 \\
$\begin{array}{l}\text { Individually } \\
\text { planned 2 }\end{array}$ & 22 & 19 & 86.0 \\
Jointly planned 2 & 8 & 8 & 100.0 \\
\hline
\end{tabular}

approximately $32 \%$ and $65 \%$ to $86 \%$ and $100 \%$, although the $100 \%$ was of a small number of errors. Table 4 shows that the teacher dealt with more errors by correcting and probing them; however, the number of errors embraced remained relatively constant over time. What our quantitative analysis does not show is whether the teacher dealt with errors differently over time from how she dealt with them initially in the first categories of lessons. Despite the quantity of embraced errors being the same across the lesson categories, the manner in which the teacher embraced errors was less time consuming in comparison to how she embraced errors in the first individually planned category of lessons ${ }^{2}$. In addition, the teacher tended to elicit more incorrect responses from a single question which was corrected with a single response in the second individually planned and jointly planned lessons. That is why there are more errors that were corrected, especially in the second individually planned lessons and the second jointly planned lesson. We now describe how the teacher's manner of dealing with errors changed compared to how she dealt with them initially.

In terms of correcting errors in the first individually planned and jointly planned sets of lessons, the teacher responded to errors using the initiation-response-evaluation cycle: the teacher asked a question, a learner responded incorrectly and an evaluation of the error followed (Brodie, Jina \& Modau, 2009). However, instead of telling the learner they were incorrect, the teacher asked other learners to evaluate the incorrect answer, which was established to be wrong. Thereafter, the teacher asked another learner to give the correct answer. This method of evaluating errors after they were made shifted in the second individually planned lessons. Instead of correcting or getting other learners to correct errors immediately after they were made, the teacher usually asked the learners if there were any other answers, which elicited more errors. Often a number of other errors arose and the teacher faced the dilemma of which errors to follow up. If she chose to correct the errors, she did not just tell learners they were wrong, but she explained to the learners why they were wrong. This method of correcting errors was prevalent in the manner in which the teacher dealt with eight of the ten errors corrected in the second individually planned lessons and four of the six errors corrected in the second jointly planned lesson. This illustrates a progression on the part of the teacher in correcting errors from providing the

2. The manner in which the teacher probed errors remained constant over time. This is because probing errors merely required the teacher to access justifications for errors. 
correct answer to a single error, to eliciting a cluster of errors, correcting them and explaining the correct answer.

In terms of the teacher's shift when embracing errors, we showed that initially the process of embracing errors was time consuming. In later lessons, the teacher managed to embrace errors, but in less time. The teacher initially addressed the errors by probing learners as to whether they agreed or disagreed with an incorrect solution. After she probed learner thinking, she suggested a pathway to follow and simplified her questions to obtain the solution. This simplification of questions could be a reason that she embraced errors in less time than in the first sets of individually planned and jointly planned lessons. We were careful to check whether the simplification of questions led to what Stein, Smith, Henningsen and Silver (2000) call task decline, because if there was too great a decline in the cognitive demands of the task it would not count as embracing errors. We classified this manner of dealing with errors as embracing errors when the teacher used the error to generate new knowledge about particular concepts.

\section{Conclusions}

In this article, we have shown that the teacher dealt with four types of mistakes, namely slips, errors derived from misconceptions, language-related errors and errors derived from the incorrect usage of the calculator.

We categorised the manner in which she dealt with the errors in three categories, namely correcting errors, probing errors and embracing errors, and showed how each of these approaches to dealing with errors provides different forms of access to knowledge. We found that most of the mistakes made throughout the four categories of lessons were conceptual in nature and that the teacher probed and embraced almost as many errors as she corrected. We also showed that the percentage of errors dealt with by the teacher across the lessons increased: from $32 \%$ and $65 \%$ to $86 \%$ and $100 \%$, although the $100 \%$ was of a small number of errors. The shifts in the teacher's practice could possibly be due to the influence of her participation in her professional learning community, which supported her to engage with learner errors; however, confirming this conjecture requires further research.

We also argued that the manner in which the teacher corrected and embraced errors changed over time. The teacher managed to elicit and correct more errors and she managed to embrace errors in less time.

Good teaching requires using learner errors constructively in class on the basis of teachers' professional knowledge and judgements. Embracing errors, as we have illustrated, has the potential to allow learners to develop a rich understanding of concepts. It is preferable that teachers embrace errors rather than correcting or probing errors, which provide learners with limited access to knowledge in comparison to the access afforded to learners when teachers embrace errors. However, we do not argue that teachers should always embrace errors, because as Hansen (2011) and our findings suggest, embracing errors may be extremely time consuming. With the demands of the curriculum, it would be difficult for teachers to constantly embrace errors. We do think however, that embracing errors may be less time consuming than reteaching and re-explaining ideas, which are not conducive to eradicating misconceptions (Borasi, 1987).

Teachers should be aware of the benefits and limitations of correcting, probing and embracing errors. Using their professional knowledge, teachers should decide when and why it is appropriate to correct, to probe and to embrace errors in light of their knowledge of the content and their learners. For example, it might not make much sense to embrace a slip. Probing or correcting slips would be a more suitable method of dealing with the mistake. In probing and embracing errors, teachers are likely to develop their learners' mathematical proficiency and reasoning skills, help them become aware of their own errors and develop a sense of agency in relation to their mathematical learning.

\section{Acknowledgements}

Funding for the DIPIP project was provided by the Gauteng Education and Development Trust and the National Research Foundation.

\section{Competing interests}

The authors declare that they have no financial or personal relationship(s) that may have inappropriately influenced them in writing this article.

\section{Authors' contributions}

A.G. (University of the Witwatersrand) and K.B. (University of the Witwatersrand) worked together on this article in discussing, drafting and refining the article. The article is based on A.G.'s research project, of which K.B. was the supervisor.

\section{References}

Adams, T.L. (2003). Reading mathematics: More than words can say. The Reading Teacher, 56(8), 786-795.

Ball, D.L., \& Bass, H. (2003). Making mathematics reasonable in school. In J. Kilpatrick, W.G. Martin, \& D.E. Schifter (Eds.), A research companion to principles and standards for school mathematics (pp. 27-44). Reston, VA: NCTM. http://dx.doi. standards for school mathematics (pp. 27
org/10.1111/j.1949-8594.2003.tb18153.x

Borasi, R. (1987). Exploring mathematics through the analysis of errors. For the Learning of Mathematics, 7(3), 2-8. Available from http://www.jstor.org/ stable/40247900

Borasi, R. (1994). Capitalizing on errors as 'springboards for inquiry': A teaching experiment. Journal for Research in Mathematics Education, 25(2), 166-208. Available from http://www.jstor.org/stable/749507

Brodie, K. (2007). Teaching with conversations: Beginnings and endings. For the Learning of Mathematics, 27(1), 17-22. Available from http://www.jstor.org/ stable/40248555

Brodie, K. (2013). The power of professional learning communities. Education as Change, 17(1), 5-18. http://dx.doi.org/10.1080/16823206.2013.773929

Brodie, K. (2014). Learning about learner errors in professional learning communities. Educational Studies in Mathematics, 85, 221-239. http://dx.doi.org/10.1007/ s10649-013-9507-1

Brodie, K., Jina, Z., \& Modau, S. (2009). Challenges in implementing the new mathematics curriculum in Grade 10: A case study. African Journal of Research in 
Mathematics, Science and Technology Education, 31(1), 19-32. http://dx.doi.org/ 10.1080/10288457.2009.10740648

Brodie, K., \& Shalem, Y. (2011). Accountability conversations: Mathematics teachers' learning through challenge and solidarity. Journal of Mathematics Teacher Education, 14(6), 419-439. http://dx.doi.org/10.1007/s10857-011-9178-8

Hansen, A. (2011). Children's errors in mathematics: Understanding common misconceptions in primary school. (2nd edn.). Exeter: Learning Matters Ltd.

Hatano, G. (1996). A conception of knowledge acquisition and its implications for mathematics education. In P. Steffe, P. Nesher, P. Cobb, G. Goldin, \& B. Gree (Eds.), Theories of mathematical learning (pp. 197-217). Mahwah, NJ: Lawrence Erlbaum.

Heinze, A., \& Reiss, K. (2007). Mistake handling activities in the mathematics classroom: Effects of an in-service teacher training on students' performance in geometry. In J.-H. Woo, H.-C. Lew, K.-S. Park, \& D.-Y. Seo (Eds.), Proceedings of the 31st Conference of the International Group for the Psychology of Mathematics Education (Vol. 3, pp. 9-16). Seoul: PME.

Ingram, J., Baldry, F., \& Pitt, A. (2013). The influence of how teachers interactionally manage mathematical mistakes on the mathematics that students experience. In B. Ubuz, C.. Haser, \& M. Mariotti (Eds.), Proceedings of the 8th Congress of the European Society of Research in Mathematics Education (pp. 1487-1495). Ankara: European Society of Research in Mathematics Education. Available from http:// cerme8.metu.edu.tr/wgpapers/WG9/WG9_Ingram.pdf
Lakatos, I. (1976). Proofs and refutations. Cambridge, UK: Cambridge University Press. http://dx.doi.org/10.1017/CBO9781139171472

Nesher, P. (1987). Towards an instructional theory: The role of students' misconceptions. For the Learning of Mathematics, 7(3), 33-39. Available from http://flm-journal.org/Articles/4582E5C6877COCBF1CFF62ABA1AA0B.pdf

Olivier, A. (1989). Handling pupils' misconceptions. Pythagoras, 21, 10-19.

Peng, A., \& Luo, Z. (2009). A framework for examining mathematics teacher knowledge as used in error analysis. For the Learning of Mathematics, 29(3), 22-25.

Prediger, S. (2010). How to develop mathematics-for-teaching and for understanding: The case of meanings of the equal sign. Journal for Mathematics Teacher Education, 13(1), 73-93. http://dx.doi.org/10.1007/ s10857-009-9119-y

Smith, J.P., DiSessa, A.A., \& Roschelle, J. (1993). Misconceptions reconceived: A constructivist analysis of knowledge in transition. Journal of the Learning Sciences, 3(2), 115-163. http://dx.doi.org/10.1207/s15327809jls0302_1

Stein, M., Smith, M., Henningsen, M., \& Silver, E. (2000). Implementing standardbased mathematics instruction: A casebook for professional development. New York, NY: Teachers College Press.

Swan, M. (2001). Dealing with misconceptions in mathematics. In P. Gates (Ed.), Issues in teaching mathematics (pp. 147-165). London: Falmer Press. 